\title{
Application and Development of Electronic Commerce in International Trade in Our Country
}

\author{
ZHENG Huan ${ }^{1, a}$ \\ ${ }^{1}$ Jiangxi college of foreign study, NanChang 330099, China \\ a cathryn1978@126.com
}

Keywords: International Trade; Foreign Trade; E-business; Competition Challenge

\begin{abstract}
With the rapid development of computer industry since the 60s of the last century, the electronic commerce arises at the historic moment; the developed countries take which as a new means in the field of international trade to continuously expand the scope of its application. As the vigorous development of electronic commerce in the global scope, it has a strong impact on traditional economic trade mode, which promotes the development of international trade to the direction of the information and also opens up a new way for the sustainable development of international trade. The 21st century will be a comprehensive electronic information age; e-commerce is widely expected to become one of the largest growth points of the global economy at the turn of the century. At present, all countries in the world attaches great importance on the development of electronic commerce, and actively promote, strive to seize the opportunity to become the international trading powers of the 21st century. Compared with the developed countries, e-commerce developed relatively late in our country, there are many difficulties and resistance. How to deal with the challenge of electronic commerce in our country foreign trade has become an urgent subject for research to solve.
\end{abstract}

\section{Definition and characteristics of electronic commerce}

\section{The definition of electronic commerce}

E-commerce began to appear in the last century in the late 90s, which is an unprecedented field of high-tech development. Because electronic commerce appeared not long before, coupled with its rapid development momentum, the industry hasn't completely understand electronic commerce, which understanding also need further discussion and conclusion and further development and perfection in practice. The uniqueness of the current definition of electronic commerce has not yet been determined.

E-commerce concept was first proposed by IBM. After being put forward, this concept was given the different description of the definition of electronic commerce including the UN organization for economic cooperation and development, governments, organizations, research institutions and academic groups according to their respective understanding.

Firstly look at the generalized definition of electronic commerce. [1]General electronic commerce includes all business activities use electronic technology. Online shopping, trading activities between enterprises and sales, procurement, recruiting, planning, and other all use electronic technology to commercial activities are included in the broad e-commerce. Nutshell, general electronic commerce refers to all business activities using electronic information technology to expand propaganda, reduce costs, create business opportunities, increase the value of sales of products and services,.

As for the definition of special e-commerce, e-commerce in its narrow sense only includes part of the business activities through the Internet. Simply put, narrow sense of electronic commerce is to traditional sales and shopping channel moved to the Internet, to break the boundaries of time and space, to effectively make sales and other business activities, for example, all online shopping activities through a variety of group, taobao, etc. The business activities not only include physical activity but also include digital products and services.

In the real trade activities, we tend to use generalized concept of E-business, thinking 
e-commerce as a platform for all business activities based on the Internet. What are all the business activities? Comprehensive business activities is to a series of activities include corporate and individual business activities of each link, , talks, trade, capital payments will all be made on the Internet.

\section{The characteristics of electronic commerce}

E-commerce has become the most important in this century enterprise economic activity in the market economic operation mode; e-commerce is a new business model of the combination of IT technology and business operation, which is a major trade under the background of new economy works. Internet itself has global characteristics; network brings great openness, and Internet inherent low cost and high efficiency operation all provides a good advantage of the foundation for the development of e-commerce, the electronic commerce and many unprecedented characteristics show than past business activities.

Business model becomes more electronic, digital with fewer links in more efficient perform. Compared with the traditional postal communication, as a means of electronic communication, the Internet has the information transmission speed, and it can transfer the very big amount of information. Packet switching technology is adopted in business activities, this makes the network application efficiency is greatly improved. [2]In comparison with traditional means of with the telephone, fax, etc, electronic communication through the Internet to transmit information cost is decreased obviously. On the other hand, the Internet Web site can run automatically in the case of no probation. Internet for transferring information showed high efficiency, low cost, which is fully reflected in the main feature of this on the transaction cost and transaction time. In e-commerce, electronic file data is transferred as electron flow instead of the actual flow of the carrier, the use of manpower and material resources cost could be greatly reduced. At the same time, we can see that the electron flow would not be the limit of time, making it possible to direct transactions between the seller and the buyer. It also greatly reduces the circulation, reduce inventory, reduce the transaction costs, shorten the production cycle of the product, to a great extent, and improve the efficiency of business activities to perform.

The globalization and open of market trade bring more opportunities and more fair competition. Through the Internet, governments around the world, enterprise groups and individual together form a huge global market, and the market can cross regional restrictions, and timely and accurately provide the goods, services, such as supply and demand information to any organizations or individuals need it. This not only creates more trade opportunities, but also make the traditional information asymmetry broken, even the small and medium-sized enterprise can have the same information resources and large enterprises, so that the market competition became more fair.

\section{The impact of e-commerce development on trade theory analysis}

\section{The technological innovation theory}

Globalization and informatization is the inevitable trend of world economic development. [3]The rapid development of information technology and the wide application of Internet make the rapid development of e-commerce, as the key competitiveness of enterprises to participate in international trade, the significance of e-commerce development of the country is becoming increasingly obvious. From the perspective of the theory of technology innovation, the application of electronic commerce technology innovation is as a new production function, realized the combination of production conditions and factors of production, or the economic effect produced by e-commerce development can be regarded as a kind of technology innovation, it improve industry and the economic efficiency of enterprises by saving the cost of production so as to improve the supply level of the whole society. The theory can be well explained as in the figure 1. 


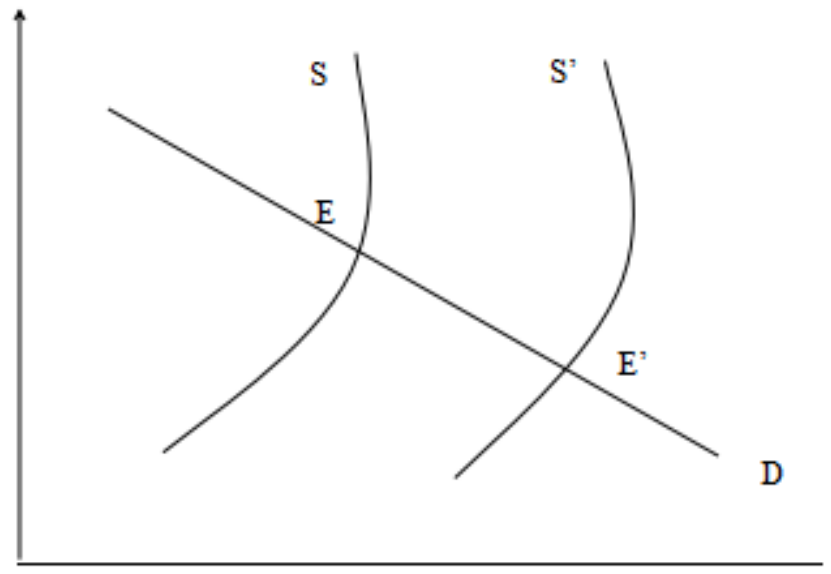

Fig 1 E-commerce $\mathrm{E}$ change the supply curve on the production level

Embodied in traditional trade production and marketing activities, entity trading patterns were often constrained by shops operating of time and place. As product sales and purchase mode generally is the main body of cross-border trade, communication between the trading main bodies also tend to be constrained by time. And under the e-commerce environment, because of the exchange and trading technology innovation, virtual enterprise, virtual bank, Internet marketing, online payment, online advertising creative services, the improvement of the trade facilitation is promoted and makes the information query, the supply of goods and part of the services, settlement and receiving such trading process can be efficiently implemented in the network. At the same time, more flexible communication through the Internet information technology promotes the efficiency of our trade activities. Therefore, the electronic commerce as a new technology collection has gradually changed the traditional trade exchanges and trade restrictions and constraints.

\section{The transaction cost theory}

According to the theory of economics, as long as communicate exchange activities are conducted, the transaction cost would be produced. [4]And under the e-commerce environment, the Internet and information technology support makes each kind of transaction costs the trade activities of the transaction costs reduced from the beginning of the trade activity to the end of the trade activities of each link of a process, so as to achieve the total cost of the trade activities, improve the efficiency of the enterprise's productivity and to participate in trade activities.

In the era of big data, business information search costs are reduced. Every trade needs to deal with a lot of information data. $90 \%$ of the enterprises in our country use computer network technology in different level, such as commodity trading center or wholesale market information network management technology to create goods and trading system, dynamic release the information such as the supply and demand and price of a commodity, reduce the consulting, trade, finance, statistics, and other cost that traditional trade activities need to spend time and manpower in consumption.

\section{The agglomeration theory}

According to the accumulative effect theory from economist Weber, a variety of industries and economic activities in the space of geographically concentrated economic effect, can promote the specialization of labor organization. Under the condition of industry, industry cluster can hedge the middlemen, and save the transaction cost, namely, industry, enterprise of agglomeration on the space can get the benefits of cost savings.

Therefore, according to the theory of industrial agglomeration economic ties in the cluster, it is the development of electronic commerce and the economic effect, technology effect that promote the development of enterprise and innovation in logistics, finance, information technology and trade and other industries. Ties between the industries and enterprises are strengthened, vertical and lateral economic ties between the industries, sectors and enterprises creates more favorable external environment for the development of trade. 
Dynamic economic activities between electronic commerce and industry or enterprise contact form an economic ecosystem on the basis of industrial agglomeration effect, resulting in huge multidirectional external economic effects. Market information sharing, technology spillover, the division of labor cooperation between enterprises or industries, makes the individual economic unit cost reduction in economic activity, thus enhance their trade competitiveness. Therefore, the development and reasonable allocation of resources of electronic commerce promote the development of foreign trade.

\section{The application and development of electronic commerce in our country foreign trade enterprise}

\section{Analysis of the present situation of electronic business in China}

1) Current situation electronic commerce development of our country

By the end of 2000, China's Internet users has reached 5.15 million, Chinese companies that have their own domain name on the Internet have been more than 2 million. According to the new research of China Internet network information center, $71.8 \%$ of Internet users are eager to shopping on the Internet. Our country has made a lot of work in terms of electronic commerce, the beneficial exploration greatly promote the development of electronic commerce in our country.

\section{2) Main gaps and problems with the development of electronic commerce in our country}

While China has done a lot of good work in the aspect of e-commerce, these can be tried for the primary stage of e-commerce. From a high standard to measure, it cannot be called the true sense of e-commerce activities. Overall, the electronic commerce development in our country is still stay in the security, confidentiality, authentication, law and other technical means and standard specification is mature and reliable. Now China's e-commerce more focus on the theoretical research, practical application is still basically in a vacuum. Our country not only needs to solve the global common problems encountered during the development process of e-commerce, but also need to solve a series of characteristic of the main problems:

\section{Electronic commerce and international trade competition}

The birth of the Internet is changing the world, and the field of international trade is influenced more, which is particularly obvious in the USA and European markets. Such as the current some famous USA retailer has said that unless supply enterprises connect to it by means of e-commerce, otherwise the delivery will not be accepted. Visible e-commerce is becoming a routine method in the field of foreign trade, and brought a new operation model to international trade, and the first entrant will benefit.

China international electronic commerce is still in its infancy, so want to through better software development, improve the wide application of international e-commerce, ultimately achieve each business through the Internet and electronic management of foreign trade and economic cooperation, realize China international electronic commerce electronic trading, gradually realize the paperless trading, this is the true sense of the international e-commerce.

\section{1) Help to increase trade opportunities}

Through the Internet, foreign trade enterprise can understand the domestic and foreign customers' commodity supply and demand situation of domestic and foreign manufacturers in very fast and convenient way. Based on the Internet, such as the "electronic trade opportunities" (ETO) provided by the United Nations Trade Network, global promotion plan provided by global resources company, etc.

\section{2) Improve the ability to carry out data exchange}

As the core part of electronic commerce electronic data interchange (ED), application in the part of the country's big companies has been very common, has been put forward only with some foreign clients to be able to use EDI data (orders, invoices) in the form of the exchange of clients for trading plan. Some enterprises with foreign investment, especially enterprise, because of its parent company for many years, has formed a complete computer management and computer network systems, urgent need through data value-added network service implementation in our country and foreign company's electronic data interchange. The occurrence of the above situation, 
make our country foreign trade enterprise for the application of EDI has is imperative, otherwise will directly affect the relationship with foreign business, can't even get the export order.

\section{Summary}

As a new mode of operation of international trade, electronic commerce will bring new vitality and opportunities to our international trade enterprises, there is no doubt that this will be the inevitable choice for the future development of China's international trade enterprises. But in contemporary international trade e-commerce boom, our enterprise should still keep sober understanding of all the advantages and disadvantages in existence, instead of blindly devoted to the construction of electronic commerce so as to avoiding redundant construction. How to use the Internet and fully participate in the international market competition is the problem that Chinese government and enterprises should think seriously about.

\section{References}

[1] Zhou Yibin, Foreign trade e-commerce: good prospect, China economic times, 2002.

[2] Zhao Liping, Introduction to e-commerce, Shanghai: Fudan university press, 2003

[3] Yang Jianzhen, Zhang Ruixia, Different types of economic in our country enterprise e-commerce application status survey analysis [J]. Journal of electronic commerce, 2012 (02), 11-18.

[4] Jin Xiuzhen. The influence of e-commerce on international trade and countermeasures [D]. Foreign Economic and Trade University, 2001. 